\title{
ECHOCARDIOGRAPHIC EVALUATION OF THE ATRIA IN SMALL ANIMALS
}

(Avaliação ecocardiográfica dos átrios em pequenos animais)

\author{
Renan Paraguassu de Sá Rodrigues ${ }^{1}$, Flávio Augusto Vieira Freitag ${ }^{1}$, Altair Aparecido Pinheiro dos \\ Santos ${ }^{2}$, Marlos Gonçalves Sousa ${ }^{3}$ \\ ${ }^{1}$ Federal University of Paraná, Graduate Program in Veterinary Sciences; ${ }^{2}$ Autonomous Veterinary \\ doctor, Curitiba - PR; ${ }^{3}$ Laboratory of Comparative Cardiology, Federal University of Paraná
}

Corresponding author: renanparaguasu@hotmail.com

RESUMO: A avaliação cardíaca muitas vezes se restringe à análise das câmaras ventriculares e, em particular, do ventrículo esquerdo. A importância da avaliação atrial foi anteriormente negligenciada, mas sua importância como representante da função cardíaca global é agora cada vez mais reconhecida. A avaliação dos átrios permite diagnósticos e monitoramento mais precisos de inúmeras doenças cardíacas. A ecocardiografia é um exame rápido, acessível e minimamente invasivo que pode fornecer dados sobre a morfologia e a função atrial. $O$ objetivo deste trabalho foi analisar as principais técnicas ecocardiográficas com potencial para serem utilizadas na avaliação dos átrios em pequenos animais.

Palavras-chave: Cardiologia; diagnóstico por imagem; dimensões; função cardíaca; volume.

ABSTRACT: Cardiac evaluation is often restricted to analysis of the ventricular chambers, and in particularthe left ventricle. The importance of atrial evaluation has previously been overlooked, but their importance as a representative of global cardiac function is now increasingly recognized. Evaluation of the atria allows more accurate diagnosis and monitoring of manyheart diseases. Echocardiography is a rapid, accessible, minimally invasive examination that can provide data onatrial morphology and function. The aim of this work was to analyze the main echocardiographic techniques with potential to be used in the evaluation of the atria in small animals.

Keywords: Cardiology; diagnostic imaging; dimensions; cardiac function; volume. 


\section{INTRODUCTION}

In contrast to assessment of the systolic and diastolic function of the ventricles, which has been widely reported in several clinical conditions, the assessment of atrial function in veterinary cardiology is still restricted to research purposes. Right atrial assessment is rarely performed, despite the recognition of its importance in overall cardiac function (Matsumoto et al., 2014). Historically, clinical, morphological, and functional evaluation of the heart is based largely on the investigation of the left heart chambers. However, the right heart is also directly, and indirectly, affected by a myriad of conditions, including pulmonary vascular disease, which can compromise cardiac function (Schober et al., 2006).

Assessment of atrial morphology is of paramount importance for the clinical stratification of manyheart diseases, since the degree of atrial dilation is related to the severity of the underlying condition. In addition, the data obtained by such evaluation, in conjunction with clinical signs, might determine treatment, predict the risk of congestive heart failure or guide followup and intervention during pre-clinical stages (Reynolds et al., 2012).

In human medicine, analysis of atrial function can aid understanding of the physiological mechanisms involved in several cardiac diseases. Recent interest in the study of atrial function, has been driven by the wide implementation of procedures involving the atria, such as the implantation of electronic devices, radiofrequency ablation and surgeries for the treatment of atrial fibrillation (Fuster et al., 2006). In veterinary medicine, although less common, similar studies ar now being performed. In dogs, the evaluation of atrial function has been shown to be useful in the diagnosis and staging of a variety ofheart diseases (Caivano et al., 2016; Nakamura et al., 2012). Studies have shown an association between echocardiographic surrogates of atrial function and the worsening of mitral valve degeneration, the most important cardiac disease in dogs (Dickson et al., 2017).

Several methods have been used to evaluate atrial function in people, including two-dimensional (2D) and three-dimensional echocardiography, imaging (Vizzardi et al., 2012). With the advances in echocardiography, many techniques have been validated that provide a more detailed assessment of atrial morphology and function, in a simple and consistent way. Of these, two-dimensional echocardiography stands out because it is widely available, non-invasive and cost-effective (Blume, Mcleod, 2011). In dogs, most studies have focused on two-dimensional echocardiographic parameters, such as the calculation of left atrial phasic sizes (areas and volumes) (Hollmer et al., 2013) and evaluation of Doppler derived transmitral and pulmonary venous flows. More recently, the use of Tissue Doppler, 3D echocardiography and speckle tracking derived strain has also been reported for atrial assessment (Le Blanc et al., 2016; Schober et al., 2010).

The objective of this study was to analyze the most important echocardiographic techniques used to evaluate the atria in animals, demonstrating the advantages and disadvantages of each. Also, we discuss the future prospects for atrial assessment in veterinary medicine and how such evaluation might aid in diagnostic procedures and prognostication of the most common cardiac diseases in pets.

\section{Left atrium}

The left atrium (LA) regulates ventricular filling through three basic functions: reservoir (during atrial 
diastole), conduit (during passive emptying in the ventricular relaxation period), and propulsive pump (in the contractionphase). The reservoir phase represents the collection of pulmonary venous flow during ventricular systole. In the conduit phase blood passes from the LA to the left ventricle (LV). Finally, the booster pump function represents the active contraction at the end of the diastole (Le Blanc et al., 2016).

These functions can be measured echocardiographically by means of volumetric calculations, whose measurements are obtained from either apical 4- or apical 2-chamber views, with the animal in left lateral recumbency (Lang et al., 2005).

In order to measure the volume and area of the LA, three techniques are recommended: the ellipsoid method, which assumes the LA is a perfect elipse.In this technique, atrial length is represented by the distance measured between the point of coaptation of the mitral valve cusps to the midpoint of the upper wall of the $A E$ and the mediallateral (transverse) dimension is obtained from a line joining the midpoint of the lateral wall to the interatrial septum, both obtained in the apical four chamber view (Figure 1). In this technique, all calculations are performed at the end of ventricular systole (Abhayaratna et al., 2006). There are twoother methods, i.e. the biplanar arealength method (Ren et al., 1983), and the Simpson's method of discs, which can be further subdivided in uniplanar and biplanar (Abhayaratna et al., 2006).
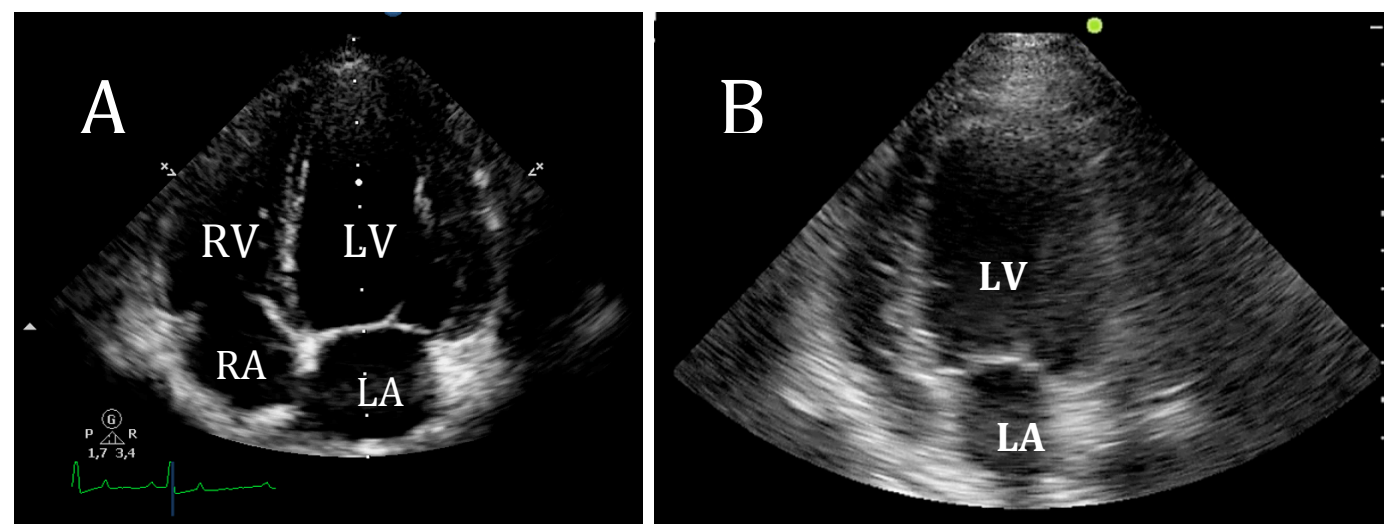

Figure 1. Apical four-chamberimage $(A)$ and two-chamber image (B) showing the right and left atria and ventricles. In this image we can obtain volumetric data, as well as mitral annulus tissue Doppler, trans-mitral flow, pulmonary venous flow and speckle-tracking derived strain and strain rate. (LA: left atrium, LV: left ventricle; RA: right atrium; RV: right ventricle).

LA volume can be calculated using the biplanar area-length method, withthe formula: LA volume $=8 / 3 \pi$ ([A1 $\times A 2] / L)=(0.85 \times A 1 \times A 2) / L$, in which A1 and A2 represent the LA planar area acquired from the apical 4- and 2chamberimages (Figure 1), $\mathrm{L}$ is the length and 0.85 is a constant. The LA area should be drawn along the inner edge of the atrial wall, excluding the confluence of the pulmonary veins and the auricle. A straight line connecting both pivot points of the mitral leaflets is taken as theboundary of the LV, thus excluding the funnel ofthe mitral valve leaflets from the LA tracing. The length of the LA is measured from the center of the plane of the mitral annulus to the upper edge of the chamber, in both the 4- and 2-chamber images, and the mean of the two is used in the formula (Hollmer et al., 2013).

Simpson's method of discs, however, considers the volume of a structure to be the sum of the volumes of smaller and similar parts. Therefore, it has been considered one of the most reliable methods for determination of the 
volume of LA in patients with heart diseases, since geometric remodeling of the LA does not compromise the resulting values. In this method two longitudinal orthogonal images, i.e. apical 2- and 4-chamber (Figure 1) are obtained from the left parasternal window. Once acquired, images are frozen at the very end of atrial diastole (beginning of the $P$ wave) and at atrial systole (end of the $P$ wave), which correspond to the opening and closing of the mitral valve leaflets respectively. Then, the left atrial endocardial borders are defined, and the resulting area is divided into several smaller cylindrical segments. The principle underlying this method is that the total LA volume is calculated from the summation of $a$ stack of elliptical discs. The height of each disc is calculated as a fraction (usually one-twentieth) of the LA long axis based on the longer of the two lengths from the two- and four-chamber views. The cross-sectional area of the disk is based on the two diameters obtained from the two- and fourchamber views. When two adequate orthogonal views are not available, a single plane can be used and the area of the disc is then assumed to be circular (Abduch, 2009).

Studies have documented contrasting results for the upper limit of normality for LA volume in dogs (0.92 $\mathrm{mL} / \mathrm{kg}$ and $1.1 \mathrm{~mL} / \mathrm{kg}$ ) when using the biplanar method. These values may provide a better basis for assessing LA size than linear dimensions when examining dogs with heart disease, since small increases in size may reflect significant increases in volume due to the asymmetric nature of atrial dilatation (Hollmer et al., 2013; Wesselowski et al., 2014).

In order to evaluate phasic function by the volumetric method, the LA volume may be measured at different times in the cardiac cycle: (1) the maximum volume of the LA is obtained at the end of the $T$ wave on the electrocardiogram, just before the opening of the mitral valve; (2) the measurement preceding atrial (preatrial) contraction at the beginning of the $P$ wave represents $L A$ volume at the end of rapid ventricular filling; (3) the minimum volume of LA is obtained at the end of ventricular diastole, i.e. just before the QRS complex (at the closure of the mitral valve). Both the area-length biplanar technique and the Simpson's method of discs are can be used for these measurements (Rodevan et al., 1999).

To describe the three phases of LA function, different parameters can be calculated (Nikitin et al., 2003):

\section{$L A$ reservoir function}

- Total emptying volume of the LA

(TEVLA):

= Maximum volume of LA - Minimum

volume of $L A(\%)$

- LA expansion index:

= TEVLA/LA minimum volume (\%)

$L A$ conduit function

- LA passive emptying volume (LAPEV):

$=L A$ maximum volume $-L A$ volume at the beginning of the $P$ wave

- Percentage of passive emptying of total emptying of LA:

$=L A P E V /($ maximum volume of $L A$ minimum volume of $L A)(\%)$

LA booster pump function

- LA active emptying volume:

= volume of the $L A$ at the beginning of the $P$ wave - minimum volume of the $L A$

- Percentage of active emptying of total LA emptying:

$=(L A$ volume at the beginning of $P$ wave - minimum volume of $L A) /($ maximum volume of $L A$ minimum volume of $L A)(\%)$

However, some factors mustbe taken into account at the time of 
analyses, since positive correlations have previously been demonstrated between left atrial volume and body weight. Also, a significant association between LA volumes and different canine breeds have been reported. Nodifferences in LA volumes related to age or sex have been reported, but LA volume decreases as heart rate (HR) increases. Thus, the reservoir, conduit and pump functions of the LAhave beenshown to have a negative correlation with HR (Hollmer et al., 2013).

\section{Evaluation by pulmonary venous flow}

The assessment of left atrial function by the analysis of pulmonary venous flow is closely linked to the hemodynamic conditions and viscoelastic properties of the LA and left ventricle (LV). In conventional echocardiography, this evaluation is accomplished by means of pulsed-wave Doppler and color flow mapping. For better visualization of the medial pulmonary vein, either 2-, 4- or 5chamber apical images should be used. The pulmonary venous flow should first be identified by color flow mapping. Subsequently, pulsed-wave Doppler is used to obtain flow velocities throughout the cardiac cycle, as well as the timevelocity integral (RIVERA et al., 2002). The typical normal pattern of pulmonary venous flowis represented by two antegrade waves, i.e. S (systolic) and D (diastolic) waves, and one retrograde wave, i.e. AR (atrial reversal). The $S$ wave is related to the decline in LA pressure during atrial relaxation after ventricular systole. At that moment, a pressure gradient is established between the pulmonary veins and the LA, which results in an antegrade systolic wave (Parashar, 2009). The Dwave, on the other hand, occurs during the opening of the mitral valve, which causes a decrease in atrial pressure and the formation of a diastolic wave. During atrial contraction, which occurs at the end of ventricular diastole, the pressure gradient between the pulmonary veins and the left atrium is reversed, causing the reflux of blood into the pulmonary veins and the formation of a retrograde wave, i.e. atrial reversal (AR) (Boon, 2011).

Although a good surrogate forLA function, assessment ofpulmonary venous flow may be difficult in animals with severe mitral insufficiency due to ventriculo-atrial regurgitation flowing into the pulmonary veins (Bonagura, Schober, 2009). Pulmonary venous flow is also difficult to assess if atrial fibrillation (AF) is present, since neither atrial contraction nor relaxation exists, therefore rsystolic pulmonary venous flow is reduced regardless of filling pressures (Nagueh et al., 2009).

\section{Evaluation by trans-mitral flow}

LA function can also be assessed by pulsed-wave Doppler measurements of early ( $E$ wave) and late (A wave) diastolic filling. To accomplish this, a sample volume should be positioned at the tip of mitral leaflets, where the peak A wave velocity is often considered a measure of LA function. In normal dogs, values of $0.61 \pm 0.12 \mathrm{~m} / \mathrm{s}$ (minimum and maximum range: $0.39-0.86$ ) are expected. This evaluation, however, is affected by age and load conditions (Chetboul et al., 2005).

\section{Assessment by Tissue Doppler Imaging}

The evaluation of the atrial deformation profile obtained by Tissue Doppler Imaging (TDI) has been proposed as an alternative method for assessing atrial function. Both 2D color and pulsed-wave Tissue Doppler provide information with sufficient temporal and spatial resolution to monitor small changes in myocardial systolic or diastolic functions (Vizzardi et al., 2012).

To perform this technique, the ultrasound equipment uses filters and 
special presets to eliminate the low frequency and high amplitude noises originating in the ventricular wall. As a result, myocardial velocityis documented instead of the blood flow velocity. This allows a better understanding of the systolic and diastolic functions of the heart, increasing the accuracy of conventional Doppler examination. In addition the information obtained from regional areas can be extrapolated to estimate global cardiac function. Finally, it has the advantage of not being significantly affected by variations in preload conditions (Toaldo et al., 2014).

The spectral profile obtained in a TDI study of the mitral annulus usually shows three large deflections, including a positive systolic wave (i.e. $S$ wave [6.4 $\pm 1.4 \mathrm{~cm} / \mathrm{s}]$ ) after a brief isovolumic contraction phase, and two negative waves (i.e. E' wave $[7.8 \pm 2.2 \mathrm{~cm} / \mathrm{s}]$ and $A^{\prime}$ wave[4.1 $\left.\pm 1.4 \mathrm{~cm} / \mathrm{s}\right]$ ), which represent the rapid ventricular filling and the atrial contraction phases, respectively (Figure $2)$. When the heart rate is rapid $E^{\prime}$ and $A^{\prime}$ waves can overlap, making the analysis difficult. Correlations between $A^{\prime}$ wave and atrial function have been described in the literature (Chetboul, 2002; Cameli et al., 2012).

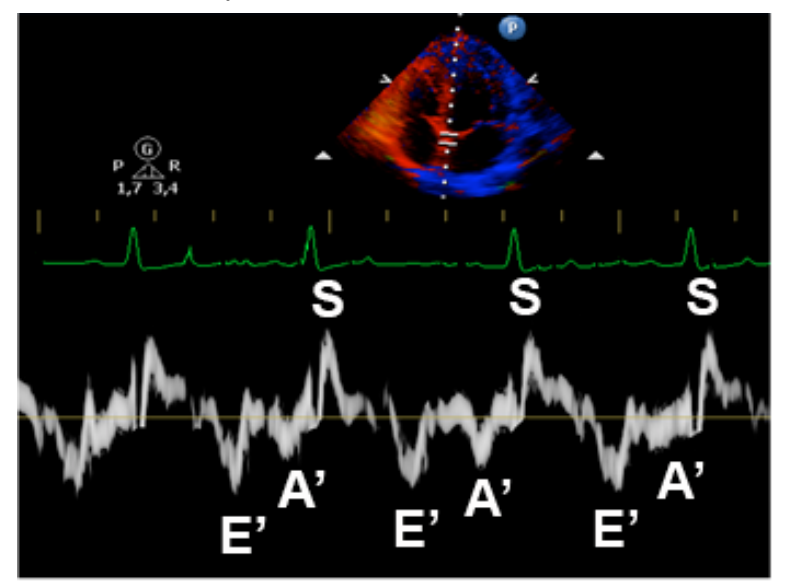

Figure 2 - Tissue Doppler study of the mitral annulus showing one systolic wave (S) and two diastolic waves (E': rapid ventricular filling; A': atrial contraction).

Because TDI is a technique that relies on the same principles of conventional Doppler, its limitations are the same. TDI requires that the cursor be aligned as parallel as possible to the assumed direction of movement of structure being analyzed. This makes it impossible for all portions of the cardiac muscle to be perfectly evaluated. Moreover, it is strongly influenced by translational movement and cannot differentiate active contraction of a normal segment from the passive contraction of an akinetic segment, i.e. a myocardial area that is only moving as a consequence of movement in an adjacent portion of normal muscule These limitations mean that TDI is gradually being replaced by more advanced and more reliablemethods, which perform independently of Doppler principles (Sousa, 2015).

\section{Evaluation by speckle tracking}

More recent technologies such as speckle tracking (STE) allow more accurate analysis of atrial function. This allows the study of strain and strain rate through two-dimensional echocardiography, evaluating the deformation in several cutting planes. With the speckle tracking technique, regional myocardial deformation can be calculated from continuous frame-byframe tracking by capturing tiny ecodense spots created by interference between the ultrasound beam and the myocardium. The movement of the speckles during the cardiac cycle follows the myocardial movement, and any change between them is understood by the equipment as myocardial deformation. Thus, STE allows assessment of myocardial function regardless of cardiac translation, insonation angle and loading conditions (To et al., 2011).

STE allows not only the documentation of the global longitudinal LA deformation, but also the individual deformation of each LA segment (Figure 3). Thus, it is possible to have information about local atrial function, with the advantage of this not being 
affected by the movement of the heart and contraction of adjacent segments (Di Salvo et al., 2005).

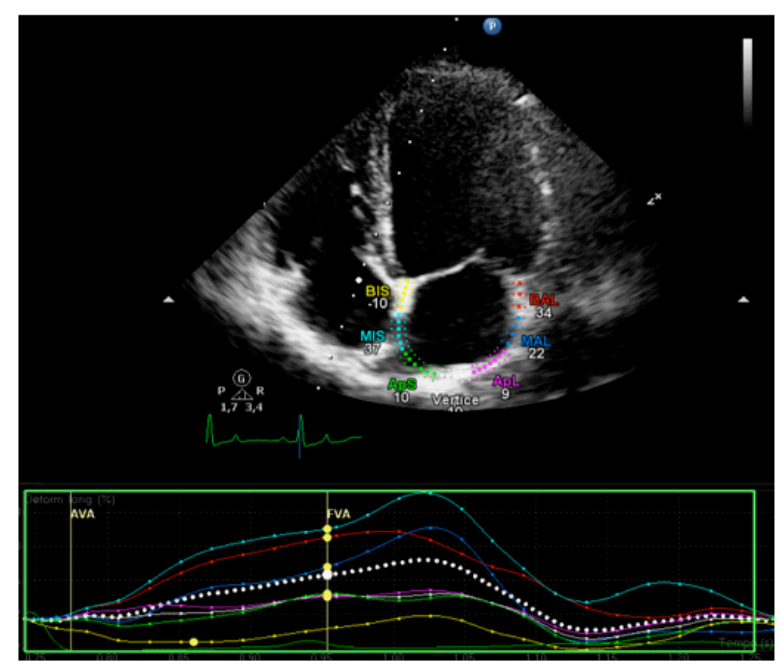

Figure 3. Left atrial strain obtained by twodimensional speckle tracking. In this analysis, the left atrium wall is automatically divided into six segments (top). Then, segmental curves are constructed (bottom) to depict left atrial deformation throughoutthe cardiac electrical cycle.

The images of the lateral and septal atrial walls are obtained from the apical 4-chamberimage (Figure 1). Older softwares required that a line be drawn manually along the LA endocardium at its minimum volume (Thomas et al., 2007). In contrast, more recent software simply requires the operator to identify two points: one at the mitral annulus and another at the top of the atrium (Wolf et al., 2018). A region of interest near the epicardium and middle myocardium lines is generated, and the image is then tracked frame by frame. The change of location of the ultrasonographic markers (speckles) represents the movement of the tissues and provides the spatial and temporal data for the calculation of velocity vectors. Quantitative curves representing all segments are expressed for each sector. The regional deformation of the LA and the strain rate curve can be analyzed in conjunction with the points in the time of the cardiac cycle, so that the relaxing and contractile functions of each segment of the LA can be assessed in detail (Vianna-Pinton et al., 2009).

However, despite the advantages, this technique also has some limitations. The reliability of the STE is particularly influenced by image quality. In addition, the currently available STE softwares are mostly designed to assess LV function and theiruse for assessment of atrial function has not yet been fully validated. The lack of standardization is also an important limitation to the widespread use of these parameters in routine clinical practice (Melzer et al., 2016).

In people, the association of STE variables with clinical status and patient prognosis has been demonstrated in numerous pathophysiological conditions typically associated with abnormal LA function, including mitral valvular degeneration, atrial fibrillation, systemic arterial hypertension, and cardiomyopathies (Vizzardi et al., 2012, Cameli et al., 2012, Vieira et al., 2014).

One study demonstrated that the peak right atrial tension (RALS) measured by 2D-STE at the end of the $\mathrm{RA}$ reservoir phase was positively correlated with systolic pulmonary artery pressure measured invasively and that assessment of longitudinal strain in the RA by 2D-STE could predict pulmonary hypertension in patients with heart failure due to left ventricular systolic dysfunction (Padeletti et al., 2011). Furthermore, the analysis of 2D-STE longitudinal deformation of the LA was well correlated with pulmonary capillary pressure (PCP), providing a better estimate of left ventricular filling pressure in patients with left ventricular dysfunction. Therefore, the measurement of RALS by 2D-STE may be useful for the estimation of RA pressure (RAP) and assessment of RA function in patients with pulmonary arterial hypertension (PAH) (Cameli et al., 2010).

More recently, one study concluded that RA longitudinal strain 
(RALS) and overall longitudinal strain rate of RA (RALSR) measured by 2DSTE were useful for the non-invasive assessment of RA dysfunction and the severity of heart failure right heart failure (RHF) in patients with PAH (Sakata et al., 2016)

In animals, there are few reports on the application of this technique for EC evaluation. However, recent research has described the use of STE for the evaluation of left atrial strain in dogs with mitral valve disease. The variables derived from this technique could be effectively obtained in animals at an advanced stage of the disease and were useful for monitoring the progressive decline of $A E$ function with the development of the disease (Toaldo et al., 2017).

\section{Right atrium}

The right atrium (RA), similar to the left, also has three basic functions, which aid right ventricular (RV) filling. The first is the reservoir function for systemic venous return when the tricuspid valve is closed. The second, a passive conduit in early ventricular diastole, when the tricuspid valve is opened. Finally, it acts as an active pump in late diastole, during atrial contraction. However, to date, few studies have evaluated right atrial function of dogs in normal and pathological situations (Vezzosi et al., 2018).

In veterinary medicine, RA enlargement is generally evaluated subjectively (Soydan et al., 2015). One study provided reference values for RA size in healthy dogs, according to allometric scales (Gentile-Solomon et al., 2016). In general, the same techniques used for volumetric calculations and analysis of the phasic functions of the LA can be used to evaluate the RA, with some adjustments inherent to this cardiac chamber. Using two-dimensional echocardiography, the
RA is best assessed from apical 4chamber images. Planimetric and volumetric methods can be used to calculate RA area and volume, respectively. RA maximal longitudinal distance is obtained from the center of the tricuspid annulus to the center of the superior wall of the RA, running in parallel to the interatrial septum. On the opposite wall, the smallest transversal distance, which is perpendicular to the long axis, is documented from the medial level of the RA free wall to the interatrial septum (Rudski et al., 2010).

The area of the RA should be evaluated by planimetry at the end of ventricular systole (i.e. just after the $T$ wave) when the greatest volume is observed. For this, a line is drawn along the endocardial border from the lateral face of the tricuspid annulus to the septal face, ensuringthe caudal and cranial vena cava and the left atrial appendage are excluded. This technique has the advantages of allowing the dimensions and area of the RA to be easily obtained from the apical 4chamber image and to allow rapid identification of right atrial dilatation. However, measurement of RA area requires longer examination time than measurements of linear dimensions alone, but it might also be a better surrogate for RV diastolic dysfunction (Rudski et al., 2010).

\section{Evaluation by speckle tracking}

As mentioned before, twodimensional STE echocardiography is a reliable technique for tracking the myocardium. This method is potentially capable of investigating RA deformation during each phase of the cardiac cycle (Vianna-Pinton et al., 2009).

In people, studies have shown that the peak RA tension measured by two-dimentsional STE at the end of the reservoir phase is correlated with the invasively-obtained systolic pulmonary artery pressure. Also, it has been 
shownthat the peak RA longitudinal tension could predict pulmonary hypertension in patients with heart failure due to left ventricular systolic dysfunction (Padeletti et al., 2011). Another study has shown that longitudinal strain and the overall longitudinal RA strain rate measured by STE were useful for the non-invasive assessment of RA dysfunction and the stratification of severity of right heart failure in patients with pulmonary arterial hypertension (Sakata et al., 2015). More recent studies have shown that RA reservoir and conduit functions were predicted mainly by indices derived from $\mathrm{RV}$ two-dimensional STE (Nourian et al., 2016).

Limitations inherent to the assessment of RA by two-dimensional STE technique are exactly the same as those observed for LA evaluation, since the principles and assessment logistics are similar.

\section{Left Atrium-to-Aorta ratio}

When it comes to LAmorphology, the most frequent measure in echocardiography is the LA-to-aortic root ratio (LA/AO). To date, several techiques have been used to obtain such parameters. In 2000 four methods were compared, namely the relationship between LA and AO diameters obtained from both short-axis and long-axis images (Figure 4 and 5 respectively), as well as the ratio between the circumferences and cross-sectional areas (Figure 6) of both structures obtained from short-axis images (Table 1) (Rishniw and Erb, 2000). Results from this study were independentof body-weight, and contrasted with result from previous studies on the same topic. In short-axis images all healthy dogs had a mean LA/AO $<1.6$ (Rishniw, Erb, 2000).

Table 1. LA/Ao described and adapted from Rishniw and Erb, 2000.

\begin{tabular}{|c|c|c|c|}
\hline Name & Axis & LA & Ao \\
\hline $\begin{array}{l}\text { SAX-LA/Ao } \\
\quad \text { (Fig. 4) }\end{array}$ & Short & $\begin{array}{l}\text { Line extending from and parallel to } \\
\text { the commissure between the left } \\
\text { and noncoronary aortic valve cusps }\end{array}$ & $\begin{array}{l}\text { Diameter along the } \\
\text { commissure between right } \\
\text { and noncoronary aortic valve } \\
\text { cusps }\end{array}$ \\
\hline $\begin{array}{l}\text { LAX-LA/Ao } \\
\text { (Fig. 5) }\end{array}$ & Long & $\begin{array}{l}\text { First line crosses the mitral valve } \\
\text { annulus, in an image frame before } \\
\text { opening of the mitral valve. Second } \\
\text { line bisects the first tothe roof of the } \\
\text { LA in apicobasilar orientation. The } \\
\text { third line, bisects the LA from the } \\
\text { interartrial septum to the LA wall in } \\
\text { the mediolateral orientation }\end{array}$ & $\begin{array}{l}\text { Same measure from SAX- } \\
\text { LA/Ao. It is not possible to } \\
\text { see the aortic valve in long- } \\
\text { axis in right parasternal 4- } \\
\text { chamber view }\end{array}$ \\
\hline $\begin{array}{l}\text { Circ-LA/Ao } \\
\text { (Fig. 6) }\end{array}$ & Short & $\begin{array}{l}\text { Circumference of LA in the same } \\
\text { image as SAX-LA/Ao }\end{array}$ & $\begin{array}{l}\text { Circumference of Ao in the } \\
\text { same image as SAX-LA/Ao }\end{array}$ \\
\hline $\begin{array}{l}\text { Area-LA/Ao } \\
\quad \text { (Fig. 6) }\end{array}$ & Short & $\begin{array}{l}\text { Internal cross-section areas } \\
\text { calculated in the same images as } \\
\text { Circ-LA/Ao }\end{array}$ & $\begin{array}{l}\text { Internal cross-section areas } \\
\text { calculated in the same } \\
\text { images as Circ-LA/Ao }\end{array}$ \\
\hline
\end{tabular}

In another study, Hansson et al. (2002) described a similar technique, which required the cursor line be positioned in the center of the aortic root, and at the junction between LA and left auricle. Their findings indicated that two-dimensional measurements of LA and $\mathrm{AO}$ using a short-axis image at the aortic valve level provide a more accurate surrogate for LA enlargement.

The classic assessment of LA in cats is obtained with the LA/AO ratio derived from longitudinal images obtained from the right parasternal window. Once the M-mode image is acquired, the LA diameter is measured 
at end-systole (i.e. just after $\mathrm{T}$ wave), whereas the aortic dimension is obtained at end-diastole (i.e. just before the QRS complex) (Aabbo, Mac Lean, 2006). Healthy cats inthat study were found to have a mean LA/AO of $1.29 \pm$ 0.13 , which contrasted with a mean of $1.58 \pm 0.38$ (Abbot, Mac Lean, 2006) for cats with hypertrophic cardiomyopathy. It is noteworthy that measurements obtained in cats using different images are not interchangeable (Haggstrom et al., 2016). Indeed, Abbot and MacLean documented different results for LA/Ao when using either longitudinal or transverse image planes. In their study, the mean LA/Ao for healthy cats was $1.41 \pm 0.14 \mathrm{~cm}$ (when longitudinal images were used) and $1.18 \pm 0.11 \mathrm{~cm}$ (when transverse images were used instead). Also, in cats with hypertrophic cardiomyopathy they found a mean of $1.75 \pm 0.42$ and $1.43 \pm 0.3$ when using longitudinal and transverse plane images, respectively.

Interestingly, the use of left atrial volume to predict left atrial enlargement seems to be a bettertechnique than LA/Ao in dogs (Wessloski et al., 2014). Nonetheless, some methods are known to underestimate the results especially if the LA is highly remodeled (Hollmer et al., 2016).

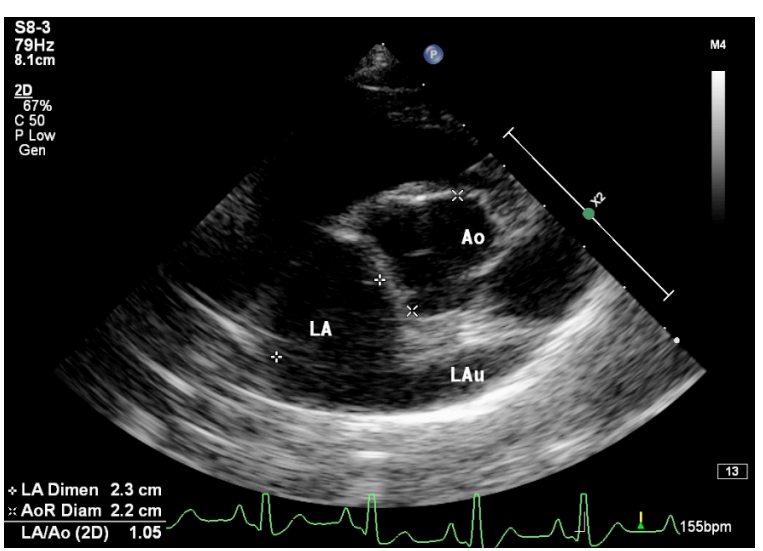

Figure 4 - Transverse image of the cardiac base at the aortic plane used to calculate the left atrium-to-aorta ratio.

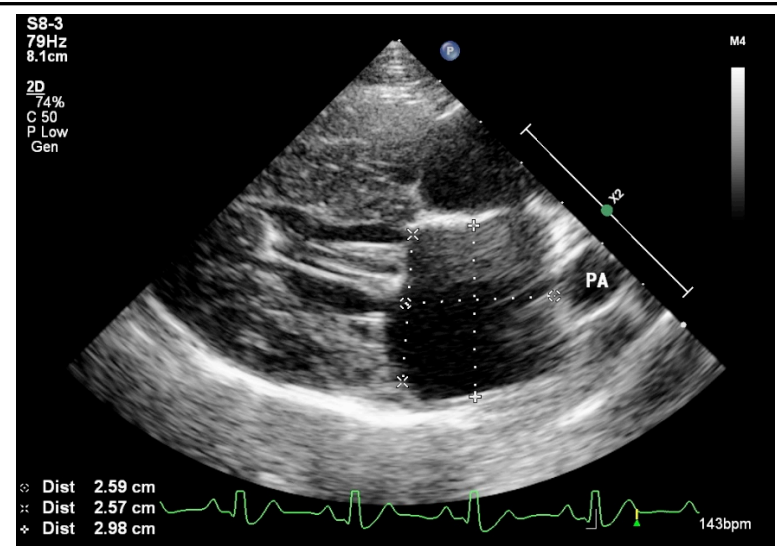

Figure 5. Cardiac longitudinal image used to measure left atrium dimensions

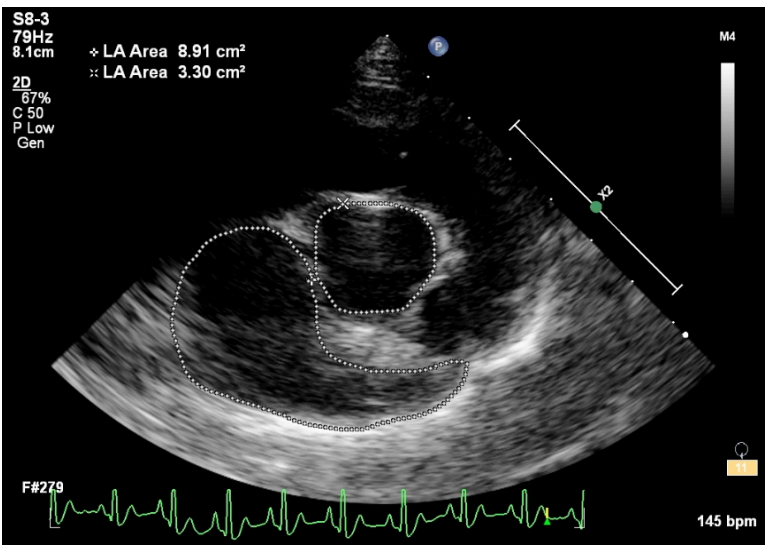

Figure 6. Transverse image of the cardiac base at the aortic plane depicting the calculation of areas of left atrium and aorta.

\section{Other comparative measuresfor atrial assessment}

In addition to morphological evaluations, some functional measures made by extrapolation from inferior vena cava (IVC) diameter can be used for the assessment of right atrial pressure (Ommen et al., 2000). In people, the IVC diameter and its inspiratory collapse may be used to predict RA pressure. The increase in RA pressure causes a dependent increase in IVC, therefore reducing its collapsibility during inspiration. This measurementrequires a long axis view of the IVC obtained from the subcostal space. An end-expiratory measurement of the diameter of the IVC should be obtained close tothe junction with the hepatic veins. It is recommended that the collapsibility of the IVC (changes in diameter) be measured during quiet respiration, to 
avoid interferences caused by the translation of the IVC. Values in mechanically ventilated patients may be different due to the positive intrathoracic pressure (Rudski et al., 2010). To the best of the author's knowledge, no reference values have been documented for dogs and cats.

In people, a correlation has been demonstrated between the electrocardiogram $P$ wave andLA size. According to an old study, subjects with a documented prolongation in $P$ wave in lead Ilhave a high probability of having increased left atrial size (Chirife et al., 1975). However, a recent investigation in dogs found a clinically unacceptable sensitivity of $P$ wave forprediction of left atrial size (Soto-Bustos et al., 2017).

\section{Transesophageal echocardiography}

Another option for cardiac evaluation is the transesophageal echocardiography, which uses a twodimensional transducer coupled to a flexible endoscope, which is introduced through the patient esophagus. This technique is capable of providing high quality images due to the closer proximity of the transducer to the heart, as well as to obtain information through Doppler (Loyer \& Thomas, 1995).

In humans, despite the advantages, several complications have been reported as painful swallowing lacerations, of the pharyngeal, dysphagia, perforations, gastric hemorrhage, and others (Hilberath et al., 2010). However, in dogs, esophageal inspection after transesophageal echocardiography procedures revealed no gross lesions indicative of trauma caused by the tube (Loyer \& Thomas, 1995).

Despite having better images, this modality has limited use in Veterinary Medicine due to the high cost and the need for specific transducers. Still, for its realization, there is a need to anesthetize patients, which increases the time and risks of the procedure (Domenech \& Oliveira, 2013). For dogs, transesophageal echo has been shown to be useful for unusual procedures, as a guide in catheterization for congenital defect occlusion such as persistent ductus arteriosus (PDA), but there are no reports of its use as a routine diagnostic technique (Saunders et al. al., 2010).

\section{FUTURE PROSPECTS FOR ATRIAL EVALUATION}

In veterinary medicine, the analysis of the atrial function, integrated with ventricular function, can potentially add fundamental information for the interpretation and understanding of the pathophysiological mechanisms and clinical signs of cardiovascular diseases that directly or indirectly involve these structures. Thus, this information can help in the diagnosis of several heart diseases and, consequently, in the prognosis, allowing implementation of an adequate and directed therapeutic protocol, improving quality of life.

Advanced technologies mean that modern equipment is becoming more accessible, so techniques for assessment of the atria are increasingly available. This is not only due to the ease of acquisition of images and tracings, but also the incorporation of new technology in systems, which allow detailed assessment of atrial dynamics. These techniques should be incorporated into echocardiographic evaluation in situations where the atria may play an important role in the compromise of global cardiac function.

\section{CONCLUSION}

Although atrial function is known to play an important role in global cardiac performance, few parameters have been validated for assessment of how cardiac diseases impair atrial contribution to cardiac function. This is especially true when it comes to 
accurately assessing right atrial function. More studies are warranted to validate indices that provideinformation about atrial function in dogs and cats in both physiologic and pathologic conditions. The use of atrial function parameters as prognostic surrogates also requires further investigation.

\section{Interest conflicts:}

The authors declare no conflicts of interest regarding the work presented in this repo.

\section{REFERECES}

ABBOTT, J.A.; MACLEAN, H.N. Twodimensional echocardiographic assessment of the feline left atrium. Journa of Veterinary Internal Medicine, v.20, p.111-119, 2006.

ABDUCH, M. C. D. Ecocardiografia. 2009. In: CARVALHO, C. F. Ultrassonografia Doppler em pequenos animais, 1. ed. São Paulo: Roca, p.201$268 \mathrm{p}$.

ABHAYARATNA, W.P.; SEWARD, J.B.; APPLETON, C.P. et al. Left atrial size: physiologic determinants and clinical applications. Journal of American College of Cardiology, v. 47, p.58-63, 2006.

BLUME, G.G.; MCLEOD, C.J. Left atrial function: physiology, assessment and clinical implications. European Journal of Echocardiography, v.12, p.421-430, 2011.

BONAGURA JD, SCHOBER KE. Can ventricular function be assessed bay echocardiography in chronic canine mitral disease? Journal of Small Animal Practice, v.50, p.12-24, 2009.

BOON, J.A.

Veterinary echocardiography. 2. ed. West Sussex: Wiley Blackwell. 2011. 632 p.

CAIVANO, D.; RISHNIW, M.; PATATA, $S$. et al. Left atrial deformation and phasic function determined by 2- dimensional speckle tracking echocardiography in healthy dogs. Journal of Veterinary Cardiology, v. 18, p.146-155, 2016.

CAMELI, M.; LISI, M.; RIGHINI, F.M.; MONDILLO, S. Novel echocardiographic techniques to assess left atrial size, anatomy and function. Cardiology and Ultrasound, v.10, p.1-13, 2012.

CAMELI, M.; LISI, M.; MONDILLO, S. et al. Left atrial longitudinal strain by speckle tracking echocardiography correlates well with left ventricular filling pressures in patients with heart failure. Cardiology and Ultrasound, v.21, p.8-14, 2010.

CHETBOUL, V. Tissue Doppler imaging: a promissing technique for quantifying regional myocardial function. Journal of Veterinary Cardiology, v.4 p.7-12, 2002.

CHETBOUL, V.; SAMPEDRANO, C.C.; CONCORDET, D. et al. Use of quantitative two-dimensional color tissue Doppler imaging for assessment of left ventricular radial and longitudinal myocardial velocities in dogs. American Journal of Veterinary Research, v.66, p.953-961, 2005.

CHIRIFE, R.; FEITOSA, G.S.; FRANKL, W.S. Electrocardiographic detection of left atrial enlargement: correlation of $P$ wave with left atrial dimension by echocardiography. British Heart Journal, v.37,p.1281-1285, 1975.

DI SALVO, G.; PACILEO, G.; CASO, P. et al. Strain rate imaging is a superior method for the assessment of regional myocardial function compared with Doppler tissue imaging: a study on patients with transcatheter device closure of atrial septal defect. J American Society of Echocardiography, v.18, p.398-400, 2005.

DICKSON, D.; CAIVANO, D.; MATOS, J.N. et al. Two-dimensional 
echocardiographic estimates of left atrial function in healthy dogs and dogs with myxomatous mitral valve disease. Journal of Veterinary Cardiology, v.19, p.469-479, 2017.

DOMENECH, O.; OLIVEIRA, P. Transoesophageal echocardiography in the dog. The Veterinary Journal, v.198, p. 329-338, 2013.

FUSTER, V.; RYDÉN, L.E.; CANNOM, D.S. et al. Guidelines for the management of patients with atrial fibrillation. A report of the American College of Cardiology/American Heart Association Task Force on Practice Guidelines and the European Society of Cardiology Committee for Practice Guidelines (Writing Committee to Revise the 2001 Guidelines for the Management of Patients With Atrial Fibrillation). Circulation, v.114, p.257354, 2006.
GAYNOR,
S.L.;
MANIAR, H.S.; PRASAD, S.M. et al. Reservoir and conduit function of right atrium: impact on right ventricular filling and cardiac output. American Journal of Physiology - Heart and Circulation Physiology, v.288, n.5, p.2140-2145, 2005.

GENTILE-SOLOMON, J.M.; ABBOTT, J.A. et al. Conventional echocardiographic assessment of the canine right heart: Reference intervals and repeatability. Journal of Veterinary Cardiology, v.18, p.234-247, 2016.

HAGGSTROM, J.; ANDERSSON, A..O.; FALK, T. et al. Effect of body weight on echocardiographic measurements in 19,866 pure-bred cats with or without heart disease. Journal of Veterinary Internal Medicine, v.30, p.1601-1611, 2016.

HANSSON, K.; HÄGGSTRÖM, J.; KVART, C. et al Left atrial to aortic root indices using two-dimensional and m-mode echocardiography in cavalier king Charles spaniels with and without left atrial enlargement. Veterinary Radiology and Ultrassound, v. 43, p.568-575, 2002.

HILBERATH, J.N.; OAKES, D.A.; SHERNAN, S.K. et al. Safety of transesophageal echocardiography. Journal of the American Society of Echocardiography, v.23, p.1115-1127, 2010.

HOLLMER, M.; WILLESEN, J.L.; TOLVER, A et al. Left atrial volume and phasic function in clinically healthy dogs of 12 different breeds. Veterinary Journal, v.197, p.639-645, 2013.

HOLLMER, M.; WILLESEN, J.L.; TOLVER, A, et al. Comparison of four echocardiographic methods to determine left atrial size in dogs. Journal of Veterinary Cardiology, v. 18, p.137-145, 2016.

LANG, R.M.; BIERIG, M.; DEVEREUX, R.B. et al. Recommendations for chamber quantification: A report from the American Society of Echocardiography's Guidelines and Standards Committee and the Chamber Quantification Writing Group, developed in conjunction with the European Association of Echocardiography, a Branch of the European Society of Cardiology. Journal of American Society of Echocardiography, v.18, p.1440-1463, 2005.

LE BLANC, N.; SCOLLAN, K.; SISSON, D. Quantitative evaluation of left atrial volume and function by onedimensional, two-dimensional, and three-dimensional echocardiography in a population of normal dogs. Journal of Veterinary Cardiology, v.18, p.336349, 2016.

LOYER, C.; THOMAS, W.P. Biplane transesophageal echocardiography in the dog: Technique, anatomy and imaging planes. Veterinary Radiology 
and Ultrasound, v.36, p.212-216, 1995.

MATSUMOTO, A.Y.; LITTWITZ, H.; DWORRAK, B. et al. Echocardiographic Evaluation of Left Atrial Function: Physiological and Clinical Aspects. Arquivo Brassileiro de Cardiologia, v. 27, p. 87-96, 2014.

MELZER, L.; FAEH-GUNZ, A.; NAEGELI, B. et al. Feasibility and limitations of 2D speckle tracking echocardiography. Cardiology Medicine, v.19, p.204-210, 2016.

MITCHELL, J.H.; SHAPIRO, W. Atrial function and the hemodynamic consequences of atrial fibrillation in man. American Journal of Cardiology, v.23, p.556-567, 1969.

NAGUEH, S.F.;
O.A.; APPLETON, C.P. et al. Recommendations for the evaluation of left ventricular diastólica function by echocardiography. Journal of American Society of Echocardiography, v.2, p.107-133, 2009.

NAKAMURA, K.; OSUGA, T.; MORISHITA, K. et al. Prognostic value of left atrial function in dogs with chronic mitral valvular heart disease. Journal of Veterinary Internal Medicine, v.28, p. 1746-1752, 2014.

NIKITIN, N.P.; WITTE, K.K.; THACKRAY, S.D. et al. Longitudinal ventricular function: normal values of atrioventricular annular and myocardial velocities measured with quantitative two-dimensional color Doppler tissue imaging. Journal of American Society of Echocardiography, v.16, n.9, p. 906921, 2003.

NOURIAN S, HOSSEINSABET A, JALALI A. et al. Evaluation of right atrial function by two-dimensional speckle tracking echocardiography in patients with right ventricular myocardial infarction. Internal Journal of

Cardiology, v.33, p.47-56, 2017.

OMMEN, S.R.; NISHIMURA, R.A.; HURRELL, D.G. et al. Assessment of right atrial pressure with 2-dimensional and Doppler echocardiography: a simultaneous catheterization and echocardiographic study. Mayo Clinics Proceedings v.75, p.24-29, 2000.

PADELETTI, M.; CAMELI, M.; LISI M. et al. Right atrial speckle tracking analysis as a novel noninvasive method for pulmonary hemodynamics assessment in patients with chronic systolic heart failure. Echocardiography, v.28, p.658664, 2011.

PARASHAR, SK. Diastolic functions: evaluation \& clinical applications. Cardiology Journal, v.1, n.2, p.132141, 2009.

REN, J.F.; KOTLER, M.N.; DEPACE, N.L. et al. Two-Dimensional Echocardiographic Determination of Left Atrial Emptying Volume: A Noninvasive Index in Quantifying the Degree of Nonrheumatic Mitral Regurgitation. Journal of American College of Cardiology, v.2, p.729-736, 1983.

REYNOLDS, C.A.; BROWN, D.C.; RUSH, J.E. et al. Prediction of first onset of congestive heart failure in dogs with degenerative mitral valve disease: the PREDICT cohort study. Journal of Veterinary Cardiology, v.14, p.193202, 2012.

RISHNIW, M.; ERB H.N. Evaluation of four 2-dimensional echocardiographic methods of assessing left atrial size in dogs. Journal of Veterinary Internal Medicine, v.14, p.429-435, 2000.

RIVERA, V.R. Identificação Ecocardiográfica do Fluxo Venoso Pulmonar. Um Indicador de Hiperfluxo Pulmonar nas Malformações Cardíacas Congênitas. Arquivo Brassileiro de Cardiologia, v.78, p.537-540, 2002. 
RODEVAN,

O.; BJORNERHEIM,

R.; LJOSLAND $M$. et al. Left atrial volumes assessed by three- and twodimensional echocardiography compared to MRI estimates. Internal Journal of Cardiology, v.15, p.397410, 2018.

RUDSKI, L.G.; LAI, W.W.; AFILALO, J. Guidelines for echocardiographic assessment of the right heart in adults: a report from the American society of echocardiography. Journal of American Society of Echocardiography, v.23, p.685-713, 2010.

SAKATA, K.; UESUGI, Y.; ISAKA, A. et al. Evaluation of right atrial function using right atrial speckle tracking analysis in patients with pulmonary artery hypertension. Journal of Echocardiography, v.14, p.30-38, 2016.

SAUNDERS, A.B.; MILLER, M.W.; GORDON, S.G. Echocardiographic and angiographic comparison of ductal dimensions in dogs with patent ductus arteriosus. Journal of Veterinary Internal Medicine, v.21, p.68-75, 2007.

SCHOBER, K.E.; HART, T.M.; STERN, J.A. et al. Detection of congestive heart failure in dogs by Doppler echocardiography. Journal of Veterinary Internal Medicine, v.24, p.1358-1368, 2010.

SOTO-BUSTOS, A.; CARO-VADILLO, A.; MARTÍNEZ-DE-MERLO, E. et al. Diagnostic accuracy of electrocardiographic $P$ wave related parameters in the assessment of left atrial size in dogs with degenerative mitral valve disease. Journal of Veterinary Medicine Science, v.79, p.1682-1698, 2017.

SOUSA, M.G.

Sistema

Cardiovascular. In: Feliciano, M.A.R.; Canola, J.C.; Vicente, W.R.R. (Eds.). Diagnóstico por imagem em cães e gatos. 4. ed. São Paulo: MedVet. 2015. 669-682 p.

SOYDAN, L.C.; KELLIHAN, H.B.; BATES, M.L. et al. Accuracy of Doppler echocardiographic estimates of pulmonary artery pressures in a canine model of pulmonary hypertension. Journal of Veterinary Cardiology, v.17, p.13-24, 2015.

THOMAS, L.; MCKAY, T.; BYTH, K. et al. Abnormalities of left atrial function after cardioversion: an atrial strain rate study. Heart, v.93, p.89-95, 2007.

TO, A.C.; FLAMM, S.D.; MARWICK, T.H. Clinical utility of multimodality LA imaging. Assessment of size, function, and structure. JACC Cardiology Imaginging, v.4, p.788-798, 2011.

TOALDO, M.B.; GUGLIELMINI, C.; DIANA, A. et al. Feasibility and reproducibility of echocardiographic assessment of regional left atrial deformation and synchrony by tissue Doppler ultrasonographic imaging in healthy dogs. American Journal of Veterinary Research, v. 75, p.59-66, 2014.

TOALDO, M.B.; ROMITO, G.; GUGLIELMINI, C. et al. Assessment of Left Atrial Deformation and Function by 2-Dimensional Speckle Tracking Echocardiography in Healthy Dogs and Dogs With Myxomatous Mitral Valve Disease. Journal of Veterinary Internal Medicine, v.31, p.641-649, 2017.

VEZZOSI, T.; DOMENECH, O.; IACONA, M. Echocardiographic Evaluation of the Right Atrial Area Index in Dogs with Pulmonary Hypertension. Journal of Veterinary Internal Medicine, v.32, p.42-47, 2018.

VIANNA-PINTON, R.; MORENO, C.A.; BAXTER, C.M, et al. Two dimensional speckle-tracking echocardiography of the left atrium: feasibility and regional contraction and relaxation differences in normal 
subjects. Journal of American Society of Echocardiography, v.22, p.299-305, 2009.

VIEIRA, M.J.; TEIXEIRA, R.; GONÇALVES, L. et al. Left atrial mechanics: Echocardiographic assessment and clinical implications. Journal of American Society of Echocardiography, v.27, p.463-478, 2014.

VIZZARDI, E.; D'ALOIA, A.; ROCCO, $E$, et al. How should we measure left atrial size and function? Journal Clinics and Ultrasound, v.40, p.155-166, 2012.

WANG, Z.; TAN, H.; ZHONG, M, et al. Strain rate imaging for noninvasive functional quantification of the left atrium in hypertensive patients with paroxysmal atrial fibrillation. Cardiology, v.109, p.15-24, 2010.

WESSELOWSKI, S.; BORGARELLI, M.; BELLO, N.M. et al.. Discrepancies in Identification of left atrial enlargement using left atrial volume versus left atrialto-aortic root ratio in dogs. Journal of Veterinary Internal Medicine, v.28, n.5, p.1527-1533, 2014.

WOLF, M.; LUCINA, S.B.; BRÜLER, B.C. Assessment of longitudinal systolic function using tissue motion annular displacement in healthy dogs. Journal of Veterinary Cardiology, v.20, p.175185, 2018. 